\title{
Considerations for Patient and Target Selection in Deep Brain Stimulation Surgery for Parkinson's Disease
}

Robert F. Dallapiazza ${ }^{1}$ - Philippe De Vloo ${ }^{1} \bullet$ Anton Fomenko $^{1} \bullet$ Darrin J. Lee ${ }^{1} \bullet$ Clement Hamani $^{1} \bullet$ Renato P. Munhoz ${ }^{2,3} \bullet$ Mojgan Hodaie ${ }^{1}$ - Andres M. Lozano ${ }^{1}$ - Alfonso Fasano Al, $^{2,4}$ • Suneil K. Kalia ${ }^{1}$

${ }^{1}$ Division of Neurosurgery, University of Toronto, Ontario, Canada; ${ }^{2}$ Edmond J. Safra Program in Parkinson's Disease, Morton and Gloria Shulman Movement Disorders Clinic, Toronto Western Hospital, UHN, Toronto, Ontario, Canada; ${ }^{3}$ Division of Neurology, University of Toronto, Toronto, Ontario, Canada; ${ }^{4}$ Krembil Research Institute, Toronto, Ontario, Canada

Author for Correspondence: Suneil K. Kalia, MD PhD, Division of Neurosurgery, Toronto Western Hospital, 399 Bathurst Street, Toronto, Ontario, Canada. E-mail: suneil.kalia@gmail.com

Doi: http://dx.doi.org/10.15586/codonpublications.parkinsonsdisease.2018.ch8

Abstract: Deep brain stimulation (DBS) is an effective treatment for improving motor symptoms of Parkinson's disease among well-selected patients. Over the past 30 years, several anatomical regions have been targeted with DBS based on prior experience in lesional neurosurgery and characteristic changes in subcortical motor regulation in Parkinson's disease. In this chapter, we provide an overview of the patient selection process and surgical procedure for DBS. We also discuss the various surgical targets for DBS in patients with Parkinson's disease. The subthalamic nucleus and the globus pallidus interna are the most

In: Parkinson's Disease: Pathogenesis and Clinical Aspects. Stoker TB, Greenland JC (Editors), Codon Publications, Brisbane, Australia. ISBN: 978-0-9944381-6-4; Doi: http://dx.doi. org/10.15586/codonpublications.parkinsonsdisease.2018

Copyright: The Authors.

Licence: This open access article is licenced under Creative Commons Attribution 4.0 International (CC BY 4.0). https://creativecommons.org/licenses/by-nc/4.0/ 
common surgical targets among patients with Parkinson's disease and have equivalent beneficial effects on motor symptoms. Most studies report 30-60\% improvement in motor score evaluations after DBS among well-selected patients. After subthalamic nucleus DBS, patients are able to reduce medications by $50 \%$ on average. In patients with globus pallidus interna DBS, stimulation has an anti-dyskinetic effect, although medication doses remain similar. DBS of the subthalamic nucleus is generally avoided in patients with a history of depression or neurocognitive impairment. Thalamic DBS ameliorates tremor, but has little effect on bradykinesia or rigidity. Finally, the pedunculopontine nucleus DBS is an emerging experimental treatment for postural and gait instability in Parkinson's disease.

Keywords: Deep brain stimulation; Globus pallidus interna; Parkinson's disease; Pedunculopontine nucleus; Subthalamic nucleus; Ventralis intermediate nucleus

\section{INTRODUCTION}

Idiopathic Parkinson's disease (PD) is the second most common progressive neurodegenerative disorder after Alzheimer's disease (AD). PD affects an estimated 600,000 people in the United States alone, with an estimated global total of 6.8 million people affected in $2015(1,2)$. The typical combination of motor features of PD is called "parkinsonism," which requires the presence of bradykinesia and the variable coexistence of other clinically defined signs: resting tremor, muscle rigidity, and postural instability. In addition, several other motor and non-motor features occur during the course of the disease, such as cognitive changes, sleep disturbances, and autonomic nervous system disorders. The hallmark pathological feature in PD is profound degeneration of the dopaminergic neurons in the substantia nigra pars compacta (SNpc). Loss of these neurons, which project widely within the striatum and pallidum, produce a state of low dopamine within the brain (3).

Levodopa and other dopamine replacement medications have been used since the 1960s and have revolutionized the treatment of PD $(4,5)$. Patients initially respond well to dopamine replacement treatment; however, over time, the beneficial effects are associated with complications such as motor fluctuations and levodopa-induced dyskinesias (LID) (6). Motor fluctuations include early wearing off, delayed on and sudden on/off phenomena, while dyskinesias occur usually during peak dose of levodopa in the form of involuntary hyperkinetic movements. These complications occur in a variable spectrum of severity and affect most, if not all, patients during the progression of the disease.

Surgical treatments such as pallidotomy and thalamotomy were used to alleviate the motor symptoms of PD and were historically introduced even prior to the development of dopamine replacement therapy (7-13). These procedures were temporarily abandoned after the introduction of dopamine replacement therapy; however, as the complications of pharmacological therapies were recognized, there was a resurgence in surgical treatments for PD (14-16). During lesioning procedures, such as thalamotomy, electrical stimulation was commonly used to test for effects and side effects prior to making permanent lesions. 
Also, high-frequency stimulation of the thalamus induced reduction in tremor severity in patients with PD (17). These findings, along with advances in implantable pulse generator devices, led to the development of deep brain stimulation (DBS) systems as we know today. DBS has been used to treat more than an estimated 120,000 neurological patients worldwide (18).

This chapter first discusses the multidisciplinary approach to patient selection for DBS surgery and the general surgical procedure for device implantation. Next, the two most common surgical targets for DBS in PD, the subthalamic nucleus (STN) and the internal segment of the globus pallidus (GPi), are discussed. Finally, studies that compared these two sites and other potential DBS targets such as the thalamus and pedunculopontine nucleus are covered.

\section{PATIENT SELECTION}

The Core Assessment Program for Neurosurgical Interventions and Transplantation in Parkinson's Disease (CAPSIT-PD) recommends that patients considered for surgical intervention should have a disease duration for at least 5 years. This time frame allows for atypical forms of parkinsonism to fully manifest, and during this time, most patients receive levodopa therapy. Patients who are candidates for surgery should show a positive response to dopamine replacement medications. Response to levodopa is generally considered to be a greater than $30 \%$ improvement in the Unified Parkinson's disease rating scale motor score (UPDRS part III). Clinical motor improvement following DBS surgery for PD closely parallels the improvement seen after levodopa challenge. Finally, CAPSIT-PD recommendations suggest that patients with preexisting dementia and severe depression should be excluded.

There is currently no evidence to indicate DBS for any of the other disorders that may mimic the classical symptoms of PD, including multiple system atrophy (MSA), progressive supranuclear palsy (PSP), corticobasal degeneration, and Lewy body dementia (Table 1). As such, it is paramount that the diagnosis of PD is confirmed by a specialist with experience in the field of movement disorders (19). Patients with a confirmed diagnosis of PD should have their symptom responsiveness to levodopa determined by a standardized levodopa challenge test. The results of this test reflect the expected potential benefit achievable with surgery (20). Another important criterion for patient selection is the presence of disabling motor fluctuations and dyskinesias despite trials of all relevant medications tested at therapeutic dosages by a specialist with experience in the field. All patients who are deemed good candidates for DBS surgery should undergo magnetic resonance imaging of the brain prior to surgery in order to rule out any secondary diagnosis or structural concerns within the brain.

A preoperative assessment by a neuropsychiatrist and neuropsychologist is also necessary for further risk stratification and identification of patients who may require closer follow-up in the postoperative period. Many patients with PD may have mild cognitive impairment or mood/behavioral impairments that should be identified and managed. In general, stable and milder forms of these abnormalities do not necessarily mean contraindication for surgery; on the other hand, more 


\section{TABLE 1 Differential diagnosis of Parkinson's disease}

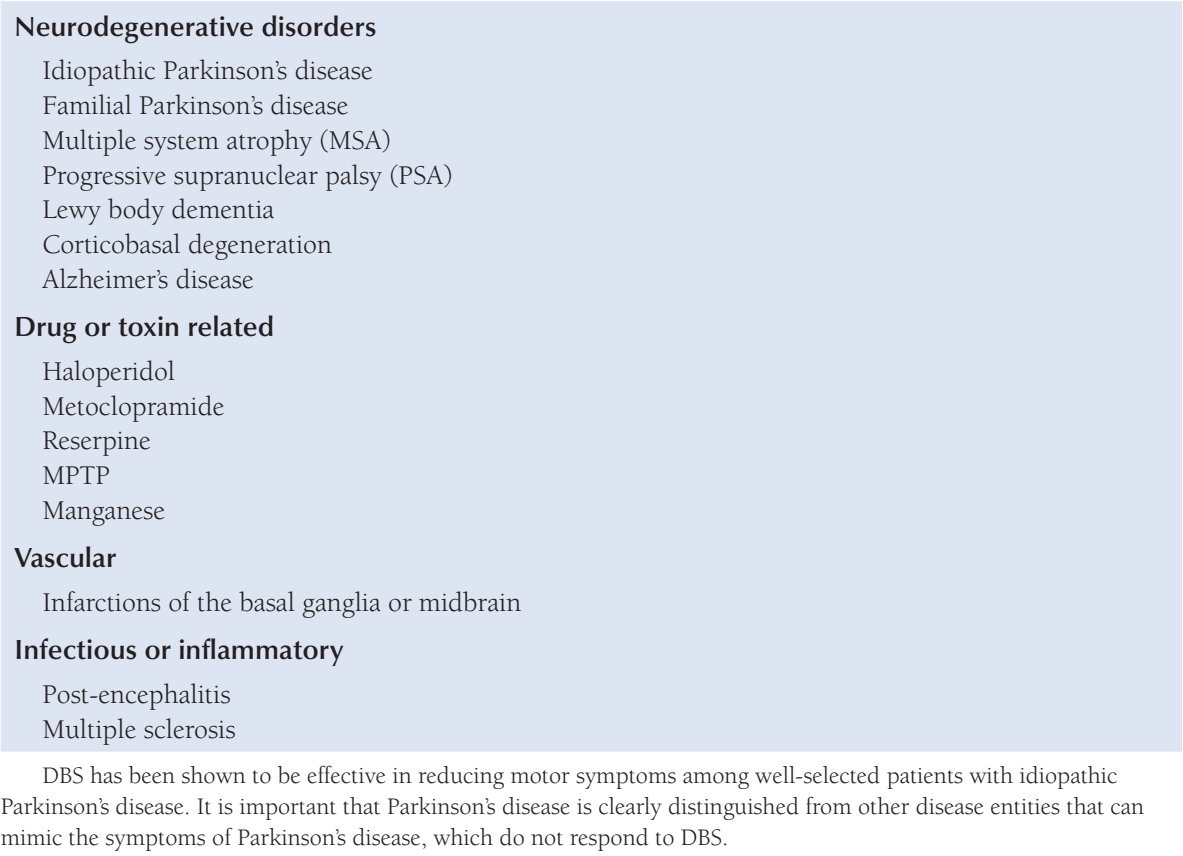

severe or progressive changes may represent risk factors for further deterioration triggered by the surgical process and/or stimulation.

Although there are no specific age limits for DBS surgery, initial clinical trials included patients who were 50-65 years old (21), while fewer studies included patients older than 75 years (22). This may reflect a general concern among referring neurologists and neurosurgeons regarding serious surgical complications, physiological reserve to recover, and rapid deterioration of motor symptoms among older patients. However, trials that have included older patients demonstrate that these patients still benefit equally from surgery without apparent further risks (22). DeLong et al. analyzed the Thomson Reuters MarketScan national database including more than 1700 patients who underwent DBS for PD between 2000 and 2009 (23). This study analyzed reported 90-day complication rates and did not find any association with increasing age (23). Further studies are needed to project the long-term outcomes of DBS surgery among elderly patients with PD.

More recently, there is evidence to suggest that DBS can improve quality of life and motor function when motor complications become evident, but before they become disabling. In a multicenter, randomized study, Schuepback et al. demonstrated that patients with early, mild PD symptoms had significant improvements in quality-of-life assessments and UPDRS part III scores compared to best medical therapy (24). Patients included in this study were younger and had shorter disease duration than those enrolled in previous, large clinical trials (discussed below) (24). This study challenges the concept that disease severity should be 
disabling before surgical intervention is delivered; however, it underlines the need for proper diagnosis before enrolling patients in surgery.

As with all elective brain surgeries, patient-specific medical conditions must be considered before proceeding to surgery. Patients who are at increased risk of perioperative complications should be medically optimized prior to any planned surgical intervention. Patients with a history of angina or coronary vascular disease should first be evaluated by a cardiologist. Patients who are taking antiplatelet agents for cardiovascular disease or anticoagulants for atrial fibrillation, pulmonary emboli, or deep venous thrombosis must temporarily stop taking these medications prior to surgery, or should be appropriately bridged with a reversible agent. Co-morbid conditions such as hypertension and diabetes should be adequately controlled to avoid intra-procedural and postoperative complications. Patient's age and overall physical condition should also be considered when risk stratifying a patient for consideration of surgery. Although there is no age limit for consideration for DBS surgery, younger patients may have better results and may tolerate the procedure better. Elderly patients or patients with significant dementia may not be good candidates for DBS surgery.

One of the most important factors in obtaining satisfactory outcomes for patients with PD after DBS is managing expectations (25). It is important to identify the patient's most disabling symptoms and to assess the patient's postoperative expectations. It is crucial to explain what the most reasonable outcomes are after surgery. This includes a candid explanation of what symptoms are likely to improve, the magnitude of improvement, and which symptoms may not improve or even worsen after surgery. If there is discord between expectations and surgical results, patients will likely be disappointed with their condition after surgery. Care should be taken when extrapolating published results during conversations with patients because of selection bias. In general, it should be emphasized that DBS serves as an "add-on" therapy, supplementing but not replacing the current therapy of the patient, aiming at improving the motor but not the non-motor symptoms of PD. It comes with risks of complications, during the implantation and during long-term care. Of note, DBS should not be presented to the patient as a cure, and despite optimal programming, the underlying PD will progress.

A critical element in determining successful surgical outcomes for patients with PD is having the support of a multidisciplinary team that specializes in the care of patients with DBS devices. This team typically includes a neurologist who is a specialist in movement disorders, a neuropsychologist who has excellent knowledge of PD and its non-motor features, and a neurosurgeon who has a specialty training in stereotactic and functional neurosurgery. Since DBS for PD was approved by the FDA, there has been a growing trend for DBS surgery to be performed at smaller hospitals with lower volumes of movement disorder surgery. Large, database studies examining the National Inpatient Sample (NIS) have demonstrated that patient outcomes after DBS surgery for PD are better when these operations are performed at hospitals with moderate or high volumes for these procedures (26). While these studies provide evidence for improved early postoperative outcomes at high-volume centers, such as favorable patient disposition and low early complication rates, it does not account for long-term patient outcomes. Device programming, managing patient medications, and general postoperative care are arguably better when provided by expert teams. 


\section{SURGICAL PROCEDURE}

The surgical procedure for implanting DBS devices can be performed with several approaches in terms of stereotactic systems, intraoperative confirmation of lead position, use of anesthesia, and staging procedures. The key components of the fully implanted system are (i) a precisely implanted intracranial electrode in the target area, (ii) implantation of lead extension wires that connect the intracranial leads to a power generating and programming source, and (iii) implantation of an internal pulse generator (Figure 1).
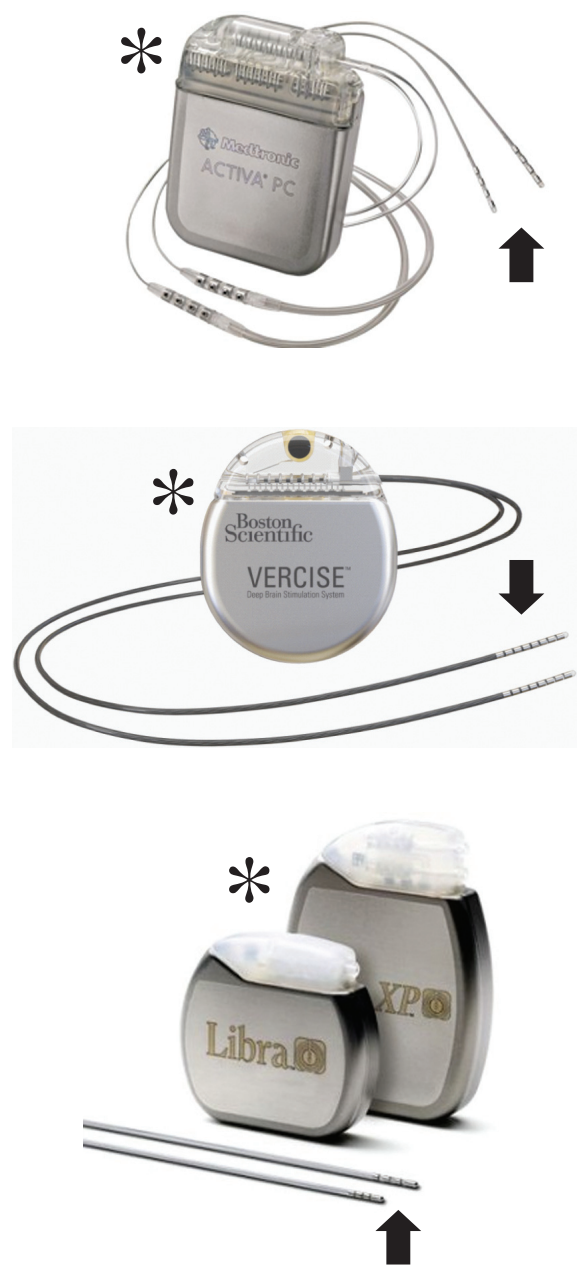

Figure 1 Current deep brain stimulation devices from Medtronic, Boston Scientific, and St. Jude's Medical. Images demonstrate internal pulse generator (indicated with ${ }^{*}$ ) and intracranial electrode with multi-contact configurations (indicated by black arrow). Images provided by Boston Scientific, Medtronic, and St. Jude's Medical and are used with permission. 
Surgery is most commonly performed while the patient is awake; however, several centers offer surgery under general anesthesia (27). There is considerable variation in the procedural details across different centers. At the Toronto Western Hospital, the surgical procedure begins by rigidly fixing a Leksell stereotactic to the patient's head under local anesthesia. The patient then undergoes stereotactic imaging with the frame in place. Several software packages are available to plan electrode targets and trajectories based on coordinate frame-based, frameless, or robotic stereotaxy.

Once the surgical plan has been made, the patient is brought to the operating room for surgery. The patient is placed in a semi-recumbent position, the hair is clipped and the scalp is prepared with betadine solution. We plan a coronally oriented incision spanning Kocher's point bilaterally, although several other incision strategies have been described. The scalp is generously blocked with local anesthetic, opened to expose the frontal bone of the skull, and the skull is trephined approximately $1 \mathrm{~cm}$ anterior to the coronal suture and at least $2 \mathrm{~cm}$ lateral from the midline. The dura is coagulated and opened. Care is taken to minimize cerebrospinal fluid loss during dural opening and throughout the procedure as this can cause brain shift.

Once dural opening is complete, a guide cannula is inserted into the brain $1-1.5 \mathrm{~cm}$ above the desired target. Microelectrode recording can then be used to identify the electrophysiological signature of the target structure and map the dorsal-ventral borders. Once a suitable tract is identified, the microelectrodes are removed and a permanent macroelectrode is inserted to the target structure. Test clinical stimulations are then performed at each of the contacts to assess for negative side effects and for clinical efficacy. Once the DBS electrode is properly situated in its final position, as verified by intra-operative fluoroscopy, it is secured to the skull and the incision is closed.

During a second procedure while the patient is under general anesthesia, the distal ends of the intracranial electrodes are connected to extension wires that are tunneled subcutaneously behind the ear down to the chest. A second incision is made $2-3 \mathrm{~cm}$ below the clavicle, and a subfascial pocket is made to house the internal pulse generator (IPG). The extension wires are connected to the IPG and the impedances for the system are assessed. Once completed, patients will typically spend one to two nights in the hospital for observation. They are brought back to the clinic 6-8 weeks later to turn on the device and begin programming.

\section{SUBTHALAMIC NUCLEUS}

The STN is a small, glutamatergic nucleus involved in the subcortical motor circuitry, measuring approximately $7 \mathrm{~mm} \times 5 \mathrm{~mm} \times 3 \mathrm{~mm}$ in dimension. As its name implies, it resides ventrally below the thalamus and zona incerta at the level of the red nucleus in the midbrain. It is bordered anteriorly by the cerebral peduncle and posteriorly by the medial lemniscus. The STN receives excitatory fibers from the cerebral cortex via the hyperdirect pathway and inhibitory inputs from the external segment of the globus pallidus (GPe) as a part of the indirect pathway. The STN sends its excitatory projections to the basal ganglia output nuclei (GPi and substantia nigra pars reticulate $[\mathrm{SNr}]$ ). 
Experimental evidence in rodent and primate models of PD suggests that the STN is critically involved in organizing basal ganglia output and has pathologically increased activity in PD (28-32). These findings were among the rationale for chronic electrical stimulation of this target which was first reported by Benabid et al. in 1994 (33). Since then, several centers have published large case series, and two large, multicenter, randomized controlled trials comparing STN DBS with best medical management have been published (Table 2) $(21,22)$.

In 2006, Deuschl et al. reported a randomized trial of neurostimulation versus best medical management among 156 patients with PD. Patients who received DBS treatment had significant improvements in UPDRS part III scores and significantly higher quality of life on PDQ-39 assessments compared to patients who received best medical therapy alone (21). Weaver et al. similarly conducted a large, multicenter, randomized trial comparing STN DBS with best medical therapy among patients with advanced PD. This study enrolled 255 patients and included patients with advanced age. Overall, among patients who received STN or GPi DBS, $71 \%$ had a $>5$ point improvement on the UPDRS part III scores (compared to $32 \%$ in best medical treatment group). Furthermore, the DBS group also experienced significant improvements in quality of life (22). The results from these two studies provide solid evidence favoring the use of STN DBS among patients with medication-refractory PD with disabling motor symptoms, dyskinesias, and motor fluctuations.

Apart from the large, randomized clinical trials, several additional studies have concluded that motor function was significantly improved after STN DBS, by 25-60\% in the "off" medication state compared to baseline motor scores (34-44). After STN DBS, patients were able to reduce dosages of dopamine replacement medications by approximately $50 \%$. Non-motor symptoms of PD did not improve among patients treated with STN DBS, and there were reports of worsening verbal fluency, mood disorders, suicide, hypophonia, and worsening postural and

\section{TABLE 2 Studies with outcome data for STN DBS}

\begin{tabular}{llclc} 
Reference & Study design & Patients, $N$ & $\begin{array}{l}\text { Study } \\
\text { duration }\end{array}$ & $\begin{array}{c}\text { UPDRS part III } \\
\text { improvement }\end{array}$ \\
\hline 20 & Randomized control trial & 156 & 6 months & $41 \%$ \\
21 & Randomized control trial & 255 & 6 months & $29 \%$ \\
33 & Case series, blinded evaluation & 18 & 10 years & $25 \%$ \\
34 & Case series, blinded evaluation & 30 & 1 year & $30 \%$ \\
35 & Case series & 23 & 5 years & $55 \%$ \\
36 & Case series & 20 & 2 years & $57 \%$ \\
38 & Case series & 7 & 1 year & $41 \%$ \\
39 & Case series & 24 & 1 year & $60 \%$ \\
42 & Case series & 19 & 2.3 years & $28 \%$ \\
43 & Case series & 15 & 1 year & $74 \%$
\end{tabular}

STN, subthalamic nucleus; DBS, deep brain stimulation; UPDRS, unified Parkinson's disease rating scale. 
gait disturbances. Since these initial reports demonstrating significant benefits after STN DBS surgery, several studies have assessed the long-term efficacy at 5 -year and 10 -year time points $(34,36,38,45)$. These studies indicate that STN DBS has continued positive benefits for patients by improved motor scores and in quality-of-life assessments.

\section{GLOBUS PALLIDUS INTERNUS}

The internal segment of the GPi is a wedge-shaped nucleus that is one of the main inhibitory output centers of the motor circuit in the basal ganglia. It is bordered laterally by the external segment of GPe and medially by the posterior limb of the internal capsule, and resides superiorly above the optic tract. The GPi receives input from the striatum, GPe, and STN and projects inhibitory fibers to the motor thalamus (Vop, Voa, and PCfc) via the ansa lenticularis and lenticular fasciculus.

Pallidotomy has long been known to improve the motor symptoms of PD $(11,12)$, and early studies comparing unilateral pallidotomy with unilateral pallidal DBS demonstrated equipoise in terms of improvement of motor symptoms (46). In 1994, Siegfried et al. first reported GPi DBS for the treatment of PD (47). Several case series have demonstrated significant improvements in motor function compared to preoperative motor evaluations (48-50). UPDRS part III scores are reported to improve by $30-50 \%$, with approximately $50 \%$ improvement in rigidity and $80 \%$ improvement in tremor. Significant improvements are also noted in dyskinesia with GPi DBS. However, unlike STN DBS, there were no decreases in dopamine replacement medications, but there were fewer overall concerns for cognitive and mood changes with GPi DBS.

\section{COMPARISON OF STN AND GPi DBS}

DBS targeting both STN and GPi has been reported to be effective in treating motor symptoms in the "off" medication state in PD patients. However, based on the initial clinical studies that described improvement in motor scores and complication rates, it was unclear whether one site provided superior outcomes compared to the other. Several studies have now been published that compared treatment outcomes with STN versus GPi DBS, including several controlled trials and a large, multi-centered, randomized trial (Table 3) (51-56).

In 2010, Follett et al. reported on 299 patients who were randomized to receive STN DBS (147 patients) or GPi DBS (152 patients) and were followed clinically for 24 months (53). Blinded assessments were performed at 6 and 24 months. In this study, there was no difference in the degree of motor improvement in the "off" medication state comparing STN with GPi stimulation at the 6- or 24-month study time points. Overall, there were no differences in complication rates between the two sites, with $56 \%$ of patients who received STN DBS reporting a serious adverse event compared to $51 \%$ of patients who received GPi DBS. Among patients who received STN DBS, there was a significant reduction in dopamine replacement medication required at 24 months compared to 


\section{TABLE 3 Studies comparing STN and GPi DBS}

\begin{tabular}{llcll} 
Reference & Study design & Patients, $N$ & $\begin{array}{l}\text { Study } \\
\text { duration }\end{array}$ & Conclusions \\
\hline 50 & Randomized, blinded & 10 & 12 months & Similar response \\
51 & Randomized, blinded & 134 & 3 months & $\begin{array}{c}\text { Both sites had significant improvements } \\
52\end{array}$ \\
Randomized, blinded & 316 & 24 months & $\begin{array}{c}\text { Both sites had similar levels of } \\
\text { improvement }\end{array}$ \\
53 & 128 & 12 months & $\begin{array}{c}\text { No difference in ADL, and STN DBS } \\
\text { had more significant improvement } \\
\text { in UPDRS III }\end{array}$ \\
54 & $\begin{array}{c}\text { Randomized } \\
\text { Retrospective, }\end{array}$ & 133 & 12 months & $\begin{array}{c}\text { Overall outcome similar for } \\
\text { dyskinesia control }\end{array}$
\end{tabular}

STN, subthalamic nucleus; GPi, globus pallidus; DBS, deep brain stimulation; ADL, activities of daily living; UPDRS, unified Parkinson's disease rating scale.

GPi DBS, which is consistent across several studies. In addition, patients who received STN DBS demonstrated a significant decrease in visual motor processing speed compared to changes seen among patients who received GPi DBS. Patients with STN DBS also had worsened depression scores compared to patients with GPi DBS (53).

Odekerken et al. (53) also performed a multicenter, randomized trial with video-blinded assessments and compared STN with GPi DBS. The primary outcomes in this study were (i) measure of functional health and (ii) composite evaluation of cognitive, mood, and behavioral effects. Secondary outcomes were symptom scales and patient questionnaires. One hundred twenty-eight patients were enrolled of whom 65 received GPi DBS and 63 received STN DBS. There were no differences in primary outcomes comparing GPi and STN DBS; however, there were larger improvements in the 'off' condition UPDRS score among patients with STN DBS. Based on these findings, the authors suggested that STN could be the preferred target for patients with advanced PD.

Most studies directly comparing STN and GPi DBS suggest that motor evaluations and improvements in quality-of-life assessments are equitable (51-56). Among patients with medication-induced dyskinesias, where one of the goals of treatment is to reduce levadopa equivalent dosages, STN DBS may be the preferred treatment. On the other hand, if reducing medication dosages is not the primary goal of treatment, GPi DBS may be used as an anti-dyskinetic therapy, without reducing medication doses.

Patients who are candidates for DBS surgery should be evaluated by a neuropsychologist for depression, cognitive impairments, and dementia. For patients with a history of depression, suicidal ideation, or suicide attempts, it is imperative to determine whether these patients are clinically stable with regard to their psychiatric health and have proper social support in place prior to enrolling in surgery. 
Among patients with a significant history of depression or mild dementia and among patients with advanced age who are otherwise good surgical candidates for DBS, some surgeons advocate for GPi DBS surgery compared to STN DBS to minimize the risks of worsening depression or cognitive changes postoperatively (57). Several early studies cited worsening depression (with suicide attempts) and impaired cognitive function after STN DBS, which prompted investigators to question whether GPi DBS may be a more suitable treatment among this patient population. However, several recent meta-analyses comparing STN and GPi DBS failed to demonstrate a significant difference between these two targets. Despite these studies, many teams continue to implant GPi DBS when there is a question of cognitive impairment, advanced patient age, or history of depression.

\section{VENTRALIS INTERMEDIATE NUCLEUS AND PEDUNCULOPONTINE NUCLEUS}

Tremor is a prominent motor feature of PD, and for patients with tremor dominant forms of PD, it may be the most disabling symptom. Thalamic lesioning procedures have been reported for more than 50 years among PD patients for relief of disabling tremor and are still used today $(9,13,58)$. Thalamic surgery for movement disorders is most commonly used among patients who have essential tremor $(\mathrm{ET})(59,60)$. The target is the ventral intermediate (Vim) thalamic nucleus. The Vim nucleus is roughly $4 \mathrm{~mm}$ in the anterior-posterior dimension and approximately 10-12 $\mathrm{mm}$ in the rostral-caudal dimension. It resides anterior to the ventrolateral caudalis nucleus, which receives somatosensory fibers from the medial lemniscus, and posterior to the ventralis oralis posterior (Vop) nucleus, which receives input from the basal ganglia. The Vim nucleus receives unconscious proprioceptive fibers from the dentatorubrothalamic tract.

Among the early studies using chronic electrical stimulation for movement disorders, the Vim nucleus was targeted as a treatment for ET and PD. However, among patients with PD, Vim stimulation was only able to alleviate tremor symptoms and was not effective for the management of the other cardinal motor symptoms such as akinesia and rigidity, which are often the more disabling symptoms of PD, especially the more common akinetic-rigid forms of PD. Accordingly, Vim DBS is most commonly used for patients with ET $(59,60)$, while STN DBS, which is also highly effective in treating tremor symptoms related to PD, is the treatment of choice among patients with PD. Vim DBS in the context of PD is reserved for those patients with tremor-dominant $\mathrm{PD}$, in whom the tremor has the largest impact on their quality of life and the other motor symptoms of PD are either mild or do not significantly impact the quality of life. It is important that patients understand the goal of the surgery is tremor control and that as PD progresses they may need additional electrodes placed at STN or GPi in the future to improve quality of life with respect to the other motor manifestations of PD.

The pedunculopontine nucleus (PPN) is a cholinergic/glutamatergic cell mass that resides caudal to the substantia nigra. It receives inhibitory and excitatory fibers from the main basal ganglia output centers (GPi and STN) and projects to 
the striatum, thalamus, spinal cord, and brainstem (61). The PPN is thought to be an important relay center involved in coordinated locomotion.

Shuffling gait and freezing are prominent, disabling features of PD; and current DBS targets do not have a significant positive impact on these symptoms when resistant to dopaminergic medications. In an effort to address this clinical need, several groups have tested PPN DBS as a treatment for gait instability related to PD (62-66). Among the centers that have reported outcomes, there has been considerable variability in patient selection, procedures performed (unilateral vs bilateral), and PPN targeting methods (67). Thus far, in studies that have conducted blinded assessments, there have not been any objective improvements; however, when PPN is stimulated with lower frequencies and in combination with STN DBS, there may be improvements in gait freezing and the number of falls (64). Further work is needed to define the role of PPN DBS in gait disturbances in $\mathrm{PD}$, and at this time, it remains an investigational but promising target.

\section{CONCLUSION}

DBS is an effective treatment for controlling many of the motor symptoms associated with PD among well-selected patients. Optimal patient outcomes can be best achieved by multidisciplinary teams (which include neurologists, neuropsychologists, and neurosurgeons), that are highly experienced in postoperative management of patients with PD. The most common targets for DBS in PD are the STN and the GPi. Both of these targets are equally effective in controlling motor symptoms in the "off" medicated state in PD. However, STN DBS is effective in reducing levodopa requirements postoperatively, while GPi DBS may have fewer negative effects on mood and cognition, especially among older patients. Vim DBS is reserved for patients whose primary disabling symptoms are tremor, and PPN DBS is an experimental treatment for patients with gait and postural instability.

Current DBS therapy is delivered as a continuous train of electrical pulses; however, many people with Parkinson's disease have fluctuations in their symptoms throughout the day. As more information about pathological neuronal firing is elucidated in Parkinson's disease, there is an effort to create DBS systems that can detect pathological brain activity and deliver electricity when these features are present. This strategy, termed closed-looped or responsive DBS, has the potential to improve symptoms of Parkinson's disease while minimizing potential complications of continuous stimulation.

Advances in DBS device engineering have improved the configuration of the intracranial electrodes and are progressing towards smaller devices with longer battery life. Currently, several device manufacturers employ "directional leads" whereby current settings can be preferentially selected to create a diverse and selective electrical field and zone of effectiveness. This may allow further programming options to minimize side effects while maximizing benefits of stimulation. Smaller internal pulse generators with longer battery lives are on the horizon, which may obviate the need for extension wires and chest implants that need to be replaced every $3-5$ years. 
Conflict of interest: P.D.V. has received grants for research from Research Foundation - Flanders and the European Society for Stereotactic and Functional Neurosurgery (ESSFN), and grants for education and travel from the World Society of Stereotactic and Functional Neurosurgery (WSSFN), Medtronic and St. Jude-Abbott. A.M.L. is a consultant for Medtronic, Boston Scientific, and Insightech. A.F. is a consultant for Abbvie, Medtronic, Boston Scientific, Sunovion, Chiesi Farmaceutici, UCB, and Ipsen. The other authors declare no potential conflicts of interest with respect to research, authorship and/or publication of this manuscript.

Copyright and permission statement: To the best of our knowledge, the materials included in this chapter do not violate copyright laws. All original sources have been appropriately acknowledged and/or referenced. Where relevant, appropriate permissions have been obtained from the original copyright holder(s). Image provided by Boston Scientific. Medtronic is providing permission to use its copyrighted images of devices and therapies but does not control whether that use conforms to Health Canada approved or cleared indications (@ 2017 Medtronic). Libra, LibraXP, and St. Jude Medical are trademarks of St. Jude Medical, LLC, or its related companies. Reproduced with permission of St. Jude Medical, (C) 2018, all rights reserved.

\section{REFERENCES}

1. Kowal SL, Dall TM, Chakrabarti R, Storm MV, Jain A. The current and projected economic burden of Parkinson's disease in the United States. Mov Disord. 2013;28(3):311-8. http://dx.doi.org/10.1002/ mds. 25292

2. Group GBDNDC. Global, regional, and national burden of neurological disorders during 1990-2015: A systematic analysis for the Global Burden of Disease Study 2015. Lancet Neurol. 2017;16(11): 877-97. http://dx.doi.org/10.1016/S1474-4422(17)30299-5

3. Kalia LV, Lang AE. Parkinson's disease. Lancet. 2015;386(9996):896-912. http://dx.doi.org/10.1016/ S0140-6736(14)61393-3

4. Fehling C. Treatment of Parkinson's syndrome with L-dopa. A double blind study. Acta Neurol Scand. 1966;42(3):367-72. http://dx.doi.org/10.1111/j.1600-0404.1966.tb01188.x

5. Cotzias GC, Papavasiliou PS, Gellene R. Modification of Parkinsonism--chronic treatment with L-dopa. N Engl J Med. 1969;280(7):337-45. http://dx.doi.org/10.1056/NEJM196902132800701

6. Muller T. Drug therapy in patients with Parkinson's disease. Transl Neurodegener. 2012;1(1):10. http://dx.doi.org/10.1186/2047-9158-1-10

7. Cooper IS. Intracerebral injection of procaine into the globus pallidus in hyperkinetic disorders. Science. 1954;119(3091):417-8. http://dx.doi.org/10.1126/science.119.3091.417

8. Cooper IS. Chemopallidectomy: An investigative technique in geriatric parkinsonians. Science. 1955;121(3137):217-8. http://dx.doi.org/10.1126/science.121.3137.217

9. Cooper IS, Bravo G. Chemopallidectomy and chemothalamectomy. J Neurosurg. 1958;15(3):244-50. http://dx.doi.org/10.3171/jns.1958.15.3.0244

10. Hurtig HI, Stern MB. Thalamotomy for Parkinson's disease. J Neurosurg. 1985;62(1):163-5.

11. Laitinen LV. Pallidotomy for Parkinson's disease. Neurosurg Clin N Am. 1995;6(1):105-12. http:// dx.doi.org/10.1016/S1042-3680(18)30479-0

12. Phillips DG. Pallidotomy and thalamotomy in Parkinson's disease. Gerontol Clin (Basel). 1961;3: 51-4. http://dx.doi.org/10.1159/000244663

13. Speakman TJ. Results of thalamotomy for Parkinson's Disease. Can Med Assoc J. 1963;89:652-6. 
14. Gross RE. What happened to posteroventral pallidotomy for Parkinson's disease and dystonia? Neurotherapeutics. 2008;5(2):281-93. http://dx.doi.org/10.1016/j.nurt.2008.02.001

15. Lozano CS, Tam J, Lozano AM. The changing landscape of surgery for Parkinson's Disease. Mov Disord. 2017;33(1):36-47.

16. Tasker RR, Siqueira J, Hawrylyshyn P, Organ LW. What happened to VIM thalamotomy for Parkinson's disease? Appl Neurophysiol. 1983;46(1-4):68-83.

17. Benabid AL, Pollak P, Louveau A, Henry S, de Rougemont J. Combined (thalamotomy and stimulation) stereotactic surgery of the VIM thalamic nucleus for bilateral Parkinson disease. Appl Neurophysiol. 1987;50(1-6):344-6.

18. Ilse Graat MFDD. The application of deep brain stimulation in the treatment of psychiatric disorders. Int Rev Psychiatr. 2017;29(2):178-90. http://dx.doi.org/10.1080/09540261.2017.1282439

19. Meissner WG, Laurencin C, Tranchant C, Witjas T, Viallet F, Guehl D, et al. Outcome of deep brain stimulation in slowly progressive multiple system atrophy: A clinico-pathological series and review of the literature. Parkinsonism Relat Disord. 2016;24:69-75. http://dx.doi.org/10.1016/j. parkreldis.2016.01.005

20. Morishita T, Rahman M, Foote KD, Fargen KM, Jacobson CEt, Fernandez HH, et al. DBS candidates that fall short on a levodopa challenge test: Alternative and important indications. Neurologist. 2011;17(5):263-8. http://dx.doi.org/10.1097/NRL.0b013e31822d1069

21. Deuschl G, Schade-Brittinger C, Krack P, Volkmann J, Schafer H, Botzel K, et al. A randomized trial of deep-brain stimulation for Parkinson's disease. N Engl J Med. 2006;355(9):896-908. http://dx.doi. org/10.1056/NEJMoa060281

22. Weaver FM, Follett K, Stern M, Hur K, Harris C, Marks WJ, Jr., et al. Bilateral deep brain stimulation vs best medical therapy for patients with advanced Parkinson disease: A randomized controlled trial. JAMA. 2009;301(1):63-73. http://dx.doi.org/10.1001/jama.2008.929

23. DeLong MR, Huang KT, Gallis J, Lokhnygina Y, Parente B, Hickey P, et al. Effect of advancing age on outcomes of deep brain stimulation for Parkinson disease. JAMA Neurol. 2014;71(10):1290-5.

24. Schuepbach WM, Rau J, Knudsen K, Volkmann J, Krack P, Timmermann L, et al. Neurostimulation for Parkinson's disease with early motor complications. N Engl J Med. 2013;368(7):610-22. http:// dx.doi.org/10.1056/NEJMoal205158

25. Knoop CD, Kadish R, Hager K, Park MC, Loprinzi PD, LaFaver K. Bridging the Gaps in patient education for DBS surgery in Parkinson's Disease. Parkinsons Dis. 2017;2017:9360354. http://dx.doi. org/10.1155/2017/9360354

26. Kalakoti P, Ahmed O, Bollam P, Missios S, Wilden J, Nanda A. Predictors of unfavorable outcomes following deep brain stimulation for movement disorders and the effect of hospital case volume on outcomes: An analysis of 33, 642 patients across 234 US hospitals using the National (Nationwide) Inpatient Sample from 2002 to 2011. Neurosurg Focus. 2015;38(6):E4. http://dx.doi. org/10.3171/2015.3.FOCUS1547

27. Ostrem JL, Ziman N, Galifianakis NB, Starr PA, Luciano MS, Katz M, et al. Clinical outcomes using ClearPoint interventional MRI for deep brain stimulation lead placement in Parkinson's disease. J Neurosurg. 2016;124(4):908-16. http://dx.doi.org/10.3171/2015.4.JNS15173

28. Bergman H, Wichmann T, DeLong MR. Reversal of experimental parkinsonism by lesions of the subthalamic nucleus. Science. 1990;249(4975):1436-8. http://dx.doi.org/10.1126/science.2402638

29. Bergman H, Wichmann T, Karmon B, DeLong MR. The primate subthalamic nucleus. II. Neuronal activity in the MPTP model of parkinsonism. J Neurophysiol. 1994;72(2):507-20. http://dx.doi. org/10.1152/jn.1994.72.2.507

30. DeLong M, Wichmann T. Update on models of basal ganglia function and dysfunction. Parkinsonism Relat Disord. 2009;15 Suppl 3:S237-40. http://dx.doi.org/10.1016/S1353-8020(09)70822-3

31. DeLong MR. Primate models of movement disorders of basal ganglia origin. Trends Neurosci. 1990;13(7):281-5. http://dx.doi.org/10.1016/0166-2236(90)90110-V

32. Obeso JA, Rodriguez-Oroz MC, Rodriguez M, Macias R, Alvarez L, Guridi J, et al. Pathophysiologic basis of surgery for Parkinson's disease. Neurology. 2000;55(12 Suppl 6):S7-12.

33. Benabid AL, Pollak P, Gross C, Hoffmann D, Benazzouz A, Gao DM, et al. Acute and long-term effects of subthalamic nucleus stimulation in Parkinson's disease. Stereotact Funct Neurosurg. 1994; 62(1-4):76-84. http://dx.doi.org/10.1159/000098600 
34. Castrioto A, Lozano AM, Poon YY, Lang AE, Fallis M, Moro E. Ten-year outcome of subthalamic stimulation in Parkinson disease: A blinded evaluation. Arch Neurol. 2011;68(12):1550-6. http:// dx.doi.org/10.1001/archneurol.2011.182

35. Ford B, Winfield L, Pullman SL, Frucht SJ, Du Y, Greene P, et al. Subthalamic nucleus stimulation in advanced Parkinson's disease: Blinded assessments at one year follow up. J Neurol Neurosurg Psychiatry. 2004;75(9):1255-9. http://dx.doi.org/10.1136/jnnp.2003.027557

36. Gervais-Bernard H, Xie-Brustolin J, Mertens P, Polo G, Klinger H, Adamec D, et al. Bilateral subthalamic nucleus stimulation in advanced Parkinson's disease: Five year follow-up. J Neurol. 2009;256(2):225-33. http://dx.doi.org/10.1007/s00415-009-0076-2

37. Herzog J, Volkmann J, Krack P, Kopper F, Potter M, Lorenz D, et al. Two-year follow-up of subthalamic deep brain stimulation in Parkinson's disease. Mov Disord. 2003;18(11):1332-7. http://dx.doi. org/10.1002/mds. 10518

38. Krack P, Batir A, Van Blercom N, Chabardes S, Fraix V, Ardouin C, et al. Five-year follow-up of bilateral stimulation of the subthalamic nucleus in advanced Parkinson's disease. N Engl J Med. 2003;349(20):1925-34. http://dx.doi.org/10.1056/NEJMoa035275

39. Kumar R, Lozano AM, Kim YJ, Hutchison WD, Sime E, Halket E, et al. Double-blind evaluation of subthalamic nucleus deep brain stimulation in advanced Parkinson's disease. Neurology. 1998;51(3):850-5. http://dx.doi.org/10.1212/WNL.51.3.850

40. Limousin P, Krack P, Pollak P, Benazzouz A, Ardouin C, Hoffmann D, et al. Electrical stimulation of the subthalamic nucleus in advanced Parkinson's disease. N Engl J Med. 1998;339(16):1105-11. http:// dx.doi.org/10.1056/NEJM199810153391603

41. Limousin P, Pollak P, Benazzouz A, Hoffmann D, Broussolle E, Perret JE, et al. Bilateral subthalamic nucleus stimulation for severe Parkinson's disease. Mov Disord. 1995;10(5):672-4. http://dx.doi. org/10.1002/mds.870100523

42. Limousin P, Pollak P, Benazzouz A, Hoffmann D, Le Bas JF, Broussolle E, et al. Effect of parkinsonian signs and symptoms of bilateral subthalamic nucleus stimulation. Lancet. 1995;345(8942):91-5. http://dx.doi.org/10.1016/S0140-6736(95)90062-4

43. Pahwa R, Wilkinson SB, Overman J, Lyons KE. Bilateral subthalamic stimulation in patients with Parkinson disease: Long-term follow up. J Neurosurg. 2003;99(1):71-7. http://dx.doi.org/10.3171/ jns.2003.99.1.0071

44. Rodriguez-Oroz MC, Gorospe A, Guridi J, Ramos E, Linazasoro G, Rodriguez-Palmero M, et al. Bilateral deep brain stimulation of the subthalamic nucleus in Parkinson's disease. Neurology. 2000;55 (12 Suppl 6):S45-51

45. Moro E, Lozano AM, Pollak P, Agid Y, Rehncrona S, Volkmann J, et al. Long-term results of a multicenter study on subthalamic and pallidal stimulation in Parkinson's disease. Mov Disord. 2010;25(5):578-86. http://dx.doi.org/10.1002/mds.22735

46. Merello M, Nouzeilles MI, Kuzis G, Cammarota A, Sabe L, Betti O, et al. Unilateral radiofrequency lesion versus electrostimulation of posteroventral pallidum: A prospective randomized comparison. Mov Disord. 1999;14(1):50-6. http://dx.doi.org/10.1002/1531-8257(199901)14:1\%3C50:: AID-MDS1010\%3E3.0.CO;2-6

47. Siegfried J, Lippitz B. Bilateral chronic electrostimulation of ventroposterolateral pallidum: A new therapeutic approach for alleviating all parkinsonian symptoms. Neurosurgery. 1994;35(6):1126-9; discussion 9-30. http://dx.doi.org/10.1227/00006123-199412000-00016

48. Kumar R, Lang AE, Rodriguez-Oroz MC, Lozano AM, Limousin P, Pollak P, et al. Deep brain stimulation of the globus pallidus pars interna in advanced Parkinson's disease. Neurology. 2000;55 (12 Suppl 6):S34-9.

49. Lyons KE, Wilkinson SB, Troster AI, Pahwa R. Long-term efficacy of globus pallidus stimulation for the treatment of Parkinson's disease. Stereotact Funct Neurosurg. 2002;79(3-4):214-20. http:// dx.doi.org/10.1159/000070834

50. Volkmann J, Allert N, Voges J, Sturm V, Schnitzler A, Freund HJ. Long-term results of bilateral pallidal stimulation in Parkinson's disease. Ann Neurol. 2004;55(6):871-5. http://dx.doi.org/10.1002/ana.20091

51. Burchiel KJ, Anderson VC, Favre J, Hammerstad JP. Comparison of pallidal and subthalamic nucleus deep brain stimulation for advanced Parkinson's disease: Results of a randomized, blinded pilot study. Neurosurgery. 1999;45(6):1375-82; discussion 82-4. http://dx.doi.org/10.1097/00006123-199912000-00024 
52. Deep-Brain Stimulation for Parkinson's Disease Study G, Obeso JA, Olanow CW, Rodriguez-Oroz MC, Krack P, Kumar R, et al. Deep-brain stimulation of the subthalamic nucleus or the pars internal of the globus pallidus in Parkinson's disease. N Engl J Med. 2001;345(13):956-63. http://dx.doi. org/10.1056/NEJMoa000827

53. Follett KA, Weaver FM, Stern M, Hur K, Harris CL, Luo P, et al. Pallidal versus subthalamic deep-brain stimulation for Parkinson's disease. N Engl J Med. 2010;362(22):2077-91. http://dx.doi.org/10.1056/ NEJMoa0907083

54. Odekerken VJ, van Laar T, Staal MJ, Mosch A, Hoffmann CF, Nijssen PC, et al. Subthalamic nucleus versus globus pallidus bilateral deep brain stimulation for advanced Parkinson's disease (NSTAPS study): A randomised controlled trial. Lancet Neurol. 2013;12(1):37-44. http://dx.doi.org/10.1016/ S1474-4422(12)70264-8

55. Oyama G, Foote KD, Jacobson CEt, Velez-Lago F, Go C, Limotai N, et al. GPi and STN deep brain stimulation can suppress dyskinesia in Parkinson's disease. Parkinsonism Relat Disord. 2012;18(7): 814-8. http://dx.doi.org/10.1016/j.parkreldis.2012.03.022

56. Weaver FM, Follett KA, Stern M, Luo P, Harris CL, Hur K, et al. Randomized trial of deep brain stimulation for Parkinson disease: Thirty-six-month outcomes. Neurology. 2012;79(1):55-65. http:// dx.doi.org/10.1212/WNL.0b013e31825dcdcl

57. Berney A, Vingerhoets F, Perrin A, Guex P, Villemure JG, Burkhard PR, et al. Effect on mood of subthalamic DBS for Parkinson's disease: A consecutive series of 24 patients. Neurology. 2002;59(9):1427-9. http://dx.doi.org/10.1212/01.WNL.0000032756.14298.18

58. Bond AE, Shah BB, Huss DS, Dallapiazza RF, Warren A, Harrison MB, et al. Safety and efficacy of focused ultrasound thalamotomy for patients with medication-refractory, Tremor-dominant Parkinson Disease: A randomized clinical trial. JAMA Neurol. 2017;74(12):1412-8. http://dx.doi.org/10.1001/ jamaneurol.2017.3098

59. Schuurman PR, Bosch DA, Bossuyt PM, Bonsel GJ, van Someren EJ, de Bie RM, et al. A comparison of continuous thalamic stimulation and thalamotomy for suppression of severe tremor. N Engl J Med. 2000;342(7):461-8. http://dx.doi.org/10.1056/NEJM200002173420703

60. Schuurman PR, Bosch DA, Merkus MP, Speelman JD. Long-term follow-up of thalamic stimulation versus thalamotomy for tremor suppression. Mov Disord. 2008;23(8):1146-53. http://dx.doi. org/10.1002/mds.22059

61. Hamani C, Aziz T, Bloem BR, Brown P, Chabardes S, Coyne T, et al. Pedunculopontine nucleus region deep brain stimulation in Parkinson Disease: Surgical anatomy and terminology. Stereotact Funct Neurosurg. 2016;94(5):298-306. http://dx.doi.org/10.1159/000449010

62. Stefani A, Lozano AM, Peppe A, Stanzione P, Galati S, Tropepi D, et al. Bilateral deep brain stimulation of the pedunculopontine and subthalamic nuclei in severe Parkinson's disease. Brain. 2007;130(Pt 6):1596-607. http://dx.doi.org/10.1093/brain/awl346

63. Ferraye MU, Debu B, Fraix V, Goetz L, Ardouin C, Yelnik J, et al. Effects of pedunculopontine nucleus area stimulation on gait disorders in Parkinson's disease. Brain. 2010;133(Pt 1):205-14. http://dx.doi. org/10.1093/brain/awp229

64. Moro E, Hamani C, Poon YY, Al-Khairallah T, Dostrovsky JO, Hutchison WD, et al. Unilateral pedunculopontine stimulation improves falls in Parkinson's disease. Brain. 2010;133(Pt 1):215-24. http:// dx.doi.org/10.1093/brain/awp261

65. Thevathasan W, Coyne TJ, Hyam JA, Kerr G, Jenkinson N, Aziz TZ, et al. Pedunculopontine nucleus stimulation improves gait freezing in Parkinson disease. Neurosurgery. 2011;69(6):1248-53; discussion 54. http://dx.doi.org/10.1227/NEU.0b013e31822b6f71

66. Khan S, Gill SS, Mooney L, White P, Whone A, Brooks DJ, et al. Combined pedunculopontine-subthalamic stimulation in Parkinson disease. Neurology. 2012;78(14):1090-5. http://dx.doi.org/10.1212/ WNL.0b013e31824e8e96

67. Thevathasan W, Debu B, Aziz T, Bloem BR, Blahak C, Butson C, et al. Pedunculopontine nucleus deep brain stimulation in Parkinson's disease: A clinical review. Mov Disord. 2017;33(1):10-20. 